\title{
Políticas DE ESCRITURA
}

Sobre Beatriz Actis (Comp). Lectura, escritura y formación docente. Rosario: Homo Sapiens, 2015. 108 pp.

Lectura, escritura y formación docente es una compilación de trabajos que abordan problemáticas que exploran desde las competencias comunicativas del siglo XXI hasta las políticas de lectura y escritura en la educación superior.

El libro está integrado por cinco artículos.

El primero, "La formación docente para las competencias comunicativas del siglo XXI", de Claudia Chamudis, se propone ampliar el concepto de alfabetización como "conocimiento y capacidad que tiene una persona para utilizar todos los sistemas semióticos de que dispone como miembro de una determinada comunidad socio-cultural" (Periant, 1987: 54) mediante la revisión de tal concepto a partir del reconocimiento de los aportes de la semiótica.

El artículo, así, se subdivide para su desarrollo en seis puntos: “¿Qué perspectiva semiótica?”, "Los procesos de comunicación", "Semiosferas", "La ilusión de transparencia en la Imagen", "Las metáforas: desde una interfaz opaca a una "casi" transparente" y "Nuevos roles ante nuevas tecnologías".

El trabajo se detiene en la irrupción de nuevas tecnologías y el cambio de rol social, principalmente docente, que ello 
supone. Sin embargo, la aparición de nuevas tecnologías es constante a lo largo de la historia de la humanidad. La autora recuerda dos puntos centrales sobre esto. Por un lado, la apreciación de Benjamin según la cual la aparición de la fotografía desplazó a los pintores, fundamentalmente a los retratistas de miniaturas. Este fenómeno causó que muchos miniaturistas se trasformaran en fotógrafos. Por otro lado, la indicación de Picasso, quien notó, a partir de la aparición de la fotografía, todo lo que ya no puede estar en el horizonte de la pintura y cómo esto la libera de la anécdota, el tema, la literatura.

Así, la autora traslada estas problemáticas al rol docente. Los roles se transforman y liberan, y el desafío de hoy es pensar cuáles serán los que competen al docente.

El trabajo cierra rescatando el desarrollo de la competencia comunicativa en sus habilidades cognitivas como la "lectura", "reflexiva", de "textos lineales", pero ampliando estas competencias a lecturas no lineales, multimediales, que incluyan funcionamientos icónicos e indiciales.

El segundo artículo, de Marcelo Díaz, se titula "Las narrativas como dispositivos pedagógicos a la hora de reflexionar sobre nuestra práctica docente".

Allí, el autor, basándose en los conceptos de "tipologías discursivas" de Bajtín, "juego de lenguaje" de Wittgenstein y "dispositivo" de Agamben, plantea la posibilidad de pensar las narrativas como medio de conocimiento de aspectos significativos de experiencias escolares, ya que las mismas problematizan los acontecimientos y visibilizan parte de la práctica docente. Su propuesta es registrar aquello que "está oculto en el funcionamiento de las instituciones $y$ que generalmente se borra en el transcurso del tiempo en las escuelas (2015: 27). En el apartado "La narración como objeto 
de lectura" el autor se detiene a analizar las ideas de narrativa, texto, y la utilización del "yo", siguiendo a Larrosa y Ricoeur. Así, afirma la importancia de construir historias que den cuenta de las subjetividades en las instituciones para dar con las propias identidades. Sin volver a las viejas formas de relatos tradicionales, el desafío es pensar la narrativa como constructora de interpretación "dentro del espacio y del tiempo en los que nos encontramos" (30).

En un segundo apartado, "Narrativas e identidades", se analiza el vínculo co-constitutivo entre ambos espacios. Pasando por la noción de performatividad del lenguaje postulada, en principio, por Austin, Díaz sostiene que justamente en la tarea de la narración se pone en juego un relato constructivo donde "somos protagonistas, narradores y autores a la vez" (32)

Los dos últimos apartados se abocan a articular lo anterior con la escuela, en "'Las narrativas y la escuela" y "La experiencia de las narrativas". En una primera instancia se pone de relieve cómo frente a las exigencias de los programas y planificaciones gubernamentales, las narrativas se plantean como manera de "producir conocimientos y como una forma de organizar y transmitir experiencias" (34). La intención de tal propuesta es que "los saberes de los docentes (tanto los formadores y formados) no queden en el olvido sino que al quedar escritos y documentados, estén disponibles para aquel que quiera utilizarlos como fuente de estudio y reflexión en el futuro" (35). Por otra parte, como posibilidad de generar en los alumnos "una inquietud para elaborar un borrador mental, o un mapa de ruta, que implique la construcción de una trama donde los acontecimientos de sus vidas se integren a una secuencia significativa" (41). 
Partiendo de testimonios de experiencias narrativas en escuelas, el artículo cierra con un párrafo de preguntas críticas donde se re cuestiona, ya incorporando los conceptos expuestos, al discurso académico. Entre ellas: “¿Por qué elegimos esas experiencias y no otras? ¿Qué argumentos, o que provocaciones, se esconden detrás del empleo de estrategias discursivas dirigidas a producir el efecto de verdad a través de la escritura de narrativas?" (44)

El tercer trabajo, "Entornos y en torno de la ortografía. Apostillas para escribir un artículo sobre la ortografía en la escritura de los textos académicos", de Annie Roth, desarrolla la práctica ortográfica y diferencia abordajes pedagógicos de su enseñanza, a partir de su propia experiencia docente.

Luego, se exponen diversas ejercitaciones (sobre tildes, homófonos, locuciones latinas, trabajo con las reglas, grafemas y fonemas), ejemplos, consignas, algunas de ellas a partir de preguntas, por ejemplo: “¿Para quién escribo, entonces?”, "¿Para qué escribir un artículo sobre ortografía en un ámbito donde se supone que "ya se sabe" o "se debería saber"...?", "¿Pedagogía de la autonomía?", "¿Qué es la ortografía, entonces? Deslindar el objeto". En base a estos desarrollos se culmina en la definición según la cual la ortografía es "una identidad gráfica de las palabras construida socialmente" (2015: 51).

"El sistema de puntuación. Análisis del fenómeno y reflexiones en torno a su enseñanza-aprendizaje", cuarto artículo del libro, de W. Koza, N. Flores, M. Hervia y G. Serrano, gira en torno al tema de la puntuación.

En principio se explicita que "Los signos de puntuación constituyen un sistema fundamental en la configuración del texto escrito, en la medida que permite la distribución y jerarquización de la información" (2015: 71), a la vez que por 
medio de ellos se puede "controlar, dirigir y promover la comprensión del lector".

Los autores se centran en los antecedentes, funciones de la puntuación en el caso de la coma, y culminan con una propuesta didáctica donde se pretende que el alumno pueda acercase al fenómeno de la puntuación "desde un empleo más efectivo y eficiente, en la medida en que deba analizar las posibilidades que brinda el sistema en la construcción (y comprensión) de significados" (2015: 83).

El último artículo, "Formulación de políticas de lectura y escritura en la educación superior. Proyecto Universidad Autónoma de Bucaramanga", propone la necesidad de que las universidades formulen, en un cruce transversal a sus cátedras, políticas de escritura y lectura para vincular a toda la comunidad universitaria reconociendo que "las dos actividades no son ajenas a las realidades colectivas de las sociedades" (2015: 87).

Atravesando diversas instancias, como la aplicación de pruebas de lectura y escritura a los estudiantes de ingreso, se crearon en esa Universidad en principio los "Talleres de habilidades comunicativas", luego la cátedra "Expresión", el proyecto de investigación "Propuesta para el desarrollo de competencias de lectura y escritura en los estudiantes de primer semestre de la UNAB". A partir de allí se propuso la cartilla "Leer para escribir" y el "Diplomado en didácticas de lectura y escritura en la Educación superior" dirigidos a docentes de la UNAB.

El artículo presenta un resumen del proyecto a partir de la estructuración en tres secciones interrogativas: “QQué es leer?", “¿Qué es escribir?”, “¿Qué es una política institucional?”. 
El último punto se centra en el "Estado del arte" y culmina con propuestas concretas para la implementación de dicho proyecto de políticas de escritura y lectura universitarias.

El libro así, articula en su totalidad modalidades dispares que se reúnen en torno a las problemáticas de la escritura, la lectura y la formación docente, que aportan tanto aspectos teóricos hondos como prácticas y propuestas novedosas que apuestan a nuevas problematizaciones de dichas temáticas, tan caras a las prácticas y experiencias de nuestra contemporaneidad. 